\title{
Experimental Investigation on the Influence of Yaw Angle on the Inlet Performance at Mach 7
}

\author{
O. Hohn ${ }^{1}$ and A. Gülhan ${ }^{2}$ \\ Wind Tunnel Department of the Institute of Aerodynamics and Flow Technology \\ German Aerospace Center (DLR) \\ Linder Höhe, 51147 Cologne, Germany
}

\begin{abstract}
[Abstract] This paper presents the results of an extensive measurement campaign that was conducted with an two-dimensional hypersonic inlet in the Hypersonic Windtunnel H2K at the German Aerospace Center in Cologne in order to study the effects of angle of yaw on the inlet performance. Both the external and internal flow paths of the inlet have been analyzed. Conducted measurements include static and Pitot pressure measurements, shadowgraph imagery, IR-thermography, Mach number and mass flow measurements. To simulate the behaviour of the inlet at different operating points, a throttle was used to impose different backpressures on the inlet.
\end{abstract}

\section{Nomenclature}

$=$ area

$=$ cylinder diameter

$=$ pressure coefficient, $c_{p}=\left(p-p_{\infty}\right) q_{\infty}^{-1}$

$=$ specific heat capacity at constant pressure

$=$ specific heat capacity at constant volume

$=$ internal compression

$=$ Mach number

$=$ mass flow

$=$ mass capture ratio

$=$ pressure

$=$ specific gas constant for air, $R=287.15 \mathrm{~J} \mathrm{~kg}^{-1} \mathrm{~K}^{-1}$

$=$ Stanton number

$=$ temperature

$=$ time

$=$ heat transfer coefficient or calibration factor

$=$ angle of yaw

$=$ specific heat ratio

$=$ throttle degree

$=$ kinetic energy efficiency

$=$ heat conductivity

$=$ total pressure recovery

$=$ density

\footnotetext{
${ }^{1} \mathrm{PhD}$ Student, Wind Tunnel Department of the Institute of Aerodynamics and Flow Technology, German Aerospace Center (DLR), Linder Höhe, 51147 Köln, Germany. Student AIAA Member.

${ }^{2}$ Head of Department, Wind Tunnel Department of the Institute of Aerodynamics and Flow Technology, German Aerospace Center (DLR), Linder Höhe, 51147 Köln, Germany. AIAA Member.
} 


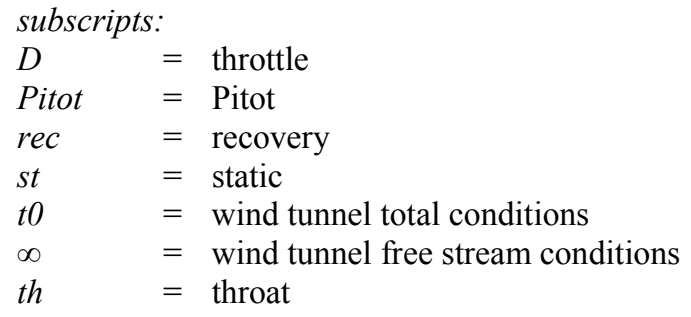

\section{Introduction}

$I^{N}$ $\mathrm{N}$ recent years a focus in the development of advanced space vehicles has been on hypersonic airbreathing propulsion, especially on scramjets where, as opposed to regular ramjets, combustion takes place at supersonic speeds. In Germany, much of the activities in this area, are concentrated in a research training group [1]. Some of the research on scramjet development of the DLR in Cologne, including the present study, is part of this project as well. During earlier activities at the DLR Windtunnel Department in Cologne in the frame of this research training group, a two-dimensional inlet model was designed and tested under different operating conditions [2, 3, 4]. The current study aims to expand and complete the database of experimental results of the operation of this inlet.

The inlet of scramjet engine has the important task of ensuring that the combustion chamber is supplied with a sufficient mass flow of air at the conditions required for supersonic combustion to take place. The quality, at which this task can be fulfilled by the inlet, is therefore crucial to the performance of the whole inlet [5]. The flow path of the inlet is very complex and contains various flow phenomena, such as shock-shock and shock-boundary-layer interaction or the formation of vortices, which have a strong influence on the flow. The existing model GK-01 was designed by use of the Method of Characteristics (MOC) as described by Anderson [6]. The inlet features a 2D double wedge ramp configuration with a horizontal lip, meaning that the deflection of the flow from the second ramp into the isolator happens by a single lip shock, which therefore is very strong. Consequently, the strong pressure rise and accordingly large pressure gradients at the interaction of the lip shock with the ramp boundarylayer causes a large separation bubble in the throat of the inlet. Besides the pressure losses induced by the separation, this separation bubble could also cause the blockage of the inlet. Therefore, a passive boundary-layer bleed was included in the inlet to ensure self-starting. The boundary-layer bleed was extensively investigated by Haeberle [3] as well as the behaviour of the inlet under different angles of attack.

This paper presents the results of a further experimental campaign with the existing inlet model GK-01 with the scope of analyzing three-dimensional flow effects in this inlet, which are induced by different angles of yaw. The purpose of this is to further examine the performance of this inlet under different flight conditions and extend the database of experimental data from previous studies $[2,4,3]$. Special interest concerning this data also comes from the development of a flight experiment configuration in the frame of the research training group. This configuration would most likely be similar to the HyShot flight experiments [7], meaning that it would fly on a parabolic trajectory, where scramjet operation is achieved during re-entry into the atmosphere. The rocket used for this kind of experiment will most likely be spin stabilized. The tumbling movements of the rocket would cause the inflow into the inlet to have an angle of yaw.

Even if the two-dimensional inlet GK-01 is operated without yaw angle, the flow is already influenced by threedimensional effects through viscous effects at the inlet sidewalls. The boundary layer at these walls causes the development of weak sidewall shocks which in turn create a very complex corner flow, as described by Henckels and Gruhn [8]. The addition of angle of yaw effects increases these effects much more. The existence of an angle of yaw induces a shock on the windward sidewall while creating a Prandtl-Meyer expansion fan on the other, which interact with the ramp flow and are reflected all the way into the isolator. Especially the sidewall shocks complicates the corner flow along the windward wall, as it creates a flow structure similar to the one described by Goonko et al. [9] for inlets with sidewall compression.

As the scramjet is intended for the use in new space vehicles, the range of applicable flight path angles is fairly small. This is also the case for a possible flight experiment. However, at flight Mach numbers around 7, even small angles can have severe influence on the inlet performance. Different angles of attack have already been examined by Haeberle and are not considered in this investigation. Therefore, only the effects of angles of yaw of up to $\beta=5^{\circ}$ have been studied. 


\section{Experimental Setup}

\section{A. Wind Tunnel and Test Conditions}

All of the experiments presented in this paper have been conducted in the Hypersonic Windtunnel $\mathrm{H} 2 \mathrm{~K}$ at the German Aerospace Centre in Cologne. This facility is a blow down wind tunnel designed to simulate Mach numbers of 5.3, 6, 7, 8.7 and 11.2 at Reynolds numbers in the range of $2.5-20 \cdot 10^{6} \mathrm{~m}^{-1}$ using contoured nozzles with an exit diameter of $600 \mathrm{~mm}$ [10]. A schematic drawing of the wind tunnel and its operating range are shown in Figure 1 and Figure 2.

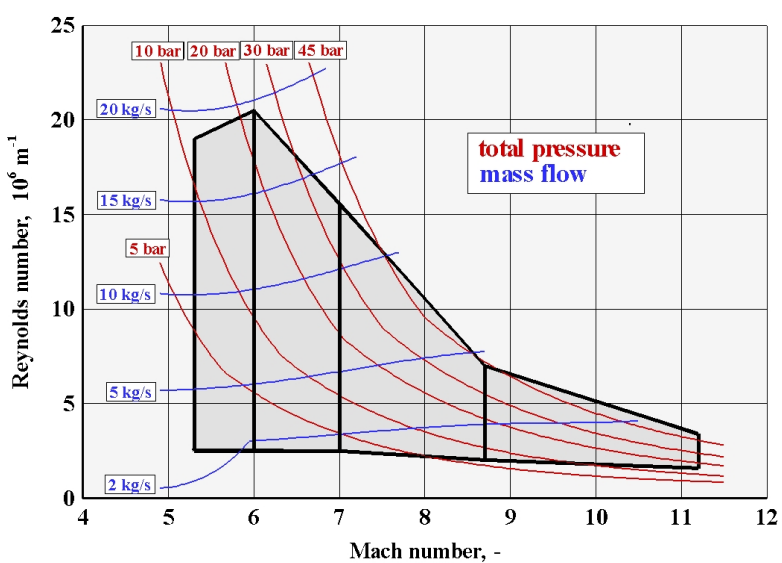

Figure 1: Performance Map of H2K

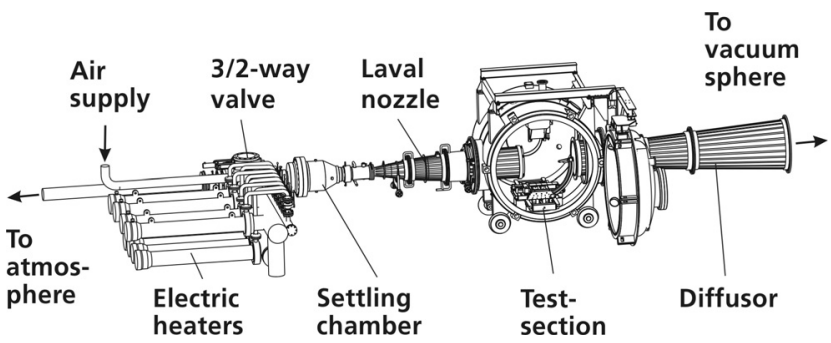

Figure 2: Schematic Drawing of H2K

To avoid condensation and to achieve different stagnation pressure and to perform aerothermal tests, the air is heated by electrical heaters with a maximum power of $5 \mathrm{MW}$. While the air is heated up, the airstream is blown into the atmosphere until the desired test condition is reached. At this point, the $3 / 2$-way valve is switched so that the flow is directed into the test chamber and out into a vacuum sphere. Depending on the flow condition, test durations of up to $30 \mathrm{~s}$ can be achieved with this tunnel

The current experimental campaign was performed at a Mach number of $M=7$. The wind tunnel flow conditions are summarized in Table 1. The angle of yaw was varied in two ways during the experiments: First, angles ranging from $\beta=0^{\circ}$ up to $4^{\circ}$ were set up before the wind tunnel run, and kept constant throughout the experiment. During the runs, the backpressure ratio $p / p_{\infty}$ was changed to simulate different pressures in the combustion chamber. Secondly, the experiments were started at $\beta=0^{\circ}$ and the angle of yaw was increased up to $5^{\circ}$, in steps of $\Delta \beta=1^{\circ}$. In these cases, the backpressure ratio was kept constant.

\begin{tabular}{|c|c|}
\hline \hline total temperature $T_{t 0}, \mathrm{~K}$ & 500 \\
\hline total pressure $p_{t 0}, \mathrm{~Pa}$ & $7.0 \cdot 10^{5}$ \\
\hline freestream Mach number $M_{\infty},-$ & 7 \\
\hline freestream pressure $p_{\infty}, \mathrm{Pa}$ & 170 \\
\hline freestream temperature $T_{\infty}, \mathrm{K}$ & 46 \\
\hline freestream density $\rho_{\infty}, \mathrm{kg} \mathrm{m}^{-3}$ & 0.0123 \\
\hline unit Reynolds number $\operatorname{Re}_{\infty, \mathrm{m}},-$ & $4.0 \cdot 10^{6}$ \\
\hline \hline
\end{tabular}

Table 1: Wind tunnel flow conditions

\section{B. Inlet Model}

For all of the experiments, the self-starting inlet model GK-01 was used. It is a two-dimensional two-ramp inlet with sidewalls, designed for a flight Mach number of $M=7.5$. Instead of an expansion corner at the throat, the inlet has an isentropic expansion surface. The internal compression ratio of this model is about $I=1-A_{t h} / A_{0}=16 \%$ and 
thus is well below the Kantrowitz and Donaldson limit, which, according to the present conditions, would allow for a maximum internal contraction ratio of $I=34 \%$ [11]. Although the inlet is self-starting, it still has a passive boundary-layer bleed integrated at the inlet throat. However, it did not prove to provide any significant advantages in the performance of the inlet in previous studies [2,3], and was therefore not used in the present investigation.

A schematic drawing of the inlet model is shown Figure 3 below, as well as a picture of the model mounted in the $\mathrm{H} 2 \mathrm{~K}$ test chamber. The ramp angles of the GK- 01 model are $\delta_{1}=7.5^{\circ}$ and $\delta_{2}=20.5^{\circ}$ to the $x$-axis. The length of the inlet from the leading edge to the defined interface with the combustion chamber is $L=0.585 \mathrm{~m}$. The throat of the inlet is located at $x=0.41 \mathrm{~m}$. Consecutively of the throat, there is a constant cross section part of $30 \mathrm{~mm}$ length. After that, the isolator is divergent by $1^{\circ}$ on the lower wall. The capture area of the inlet is $A_{0}=0.01 \mathrm{~m}^{2}(100 \mathrm{~mm} x$ $100 \mathrm{~mm}$ ).

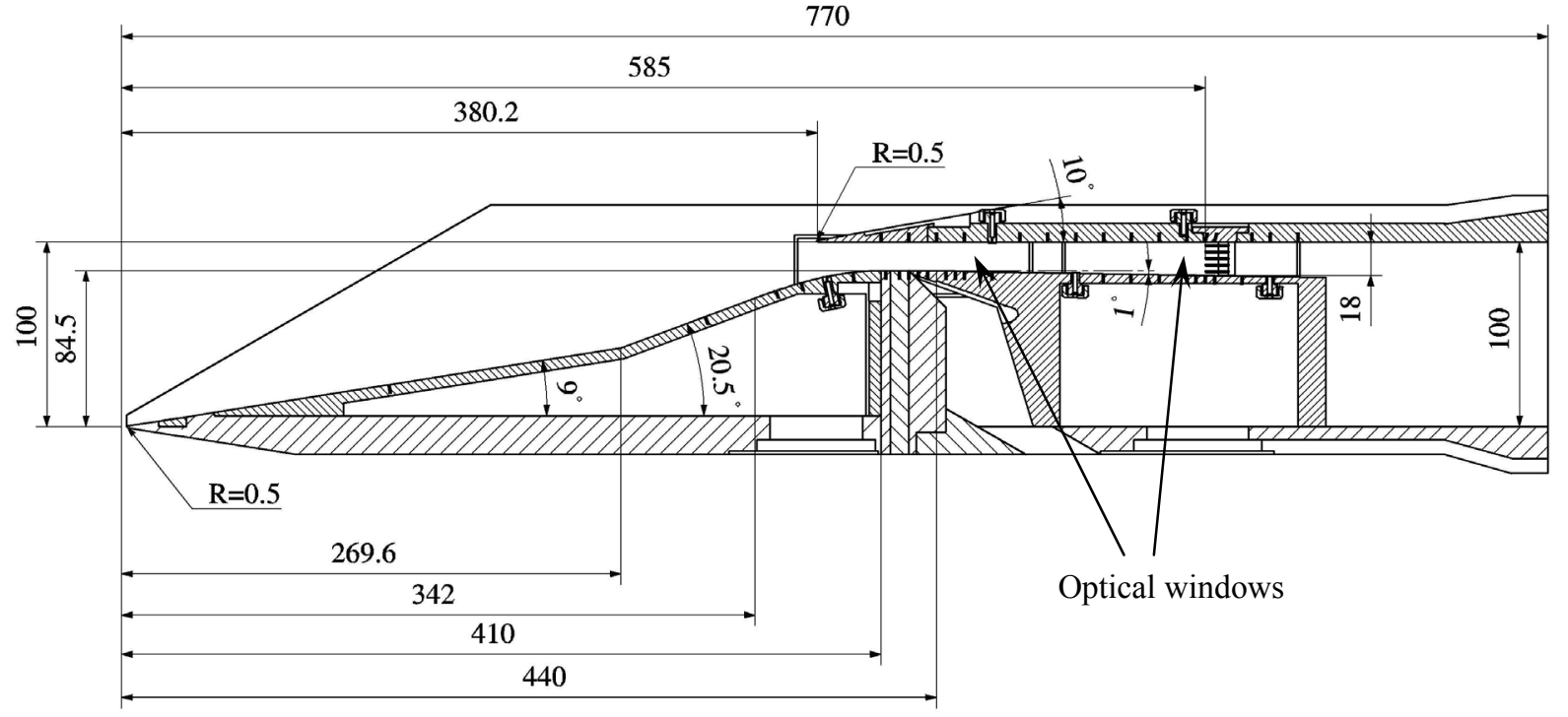

Figure 3: Cut Drawing of the Inlet Model GK-01

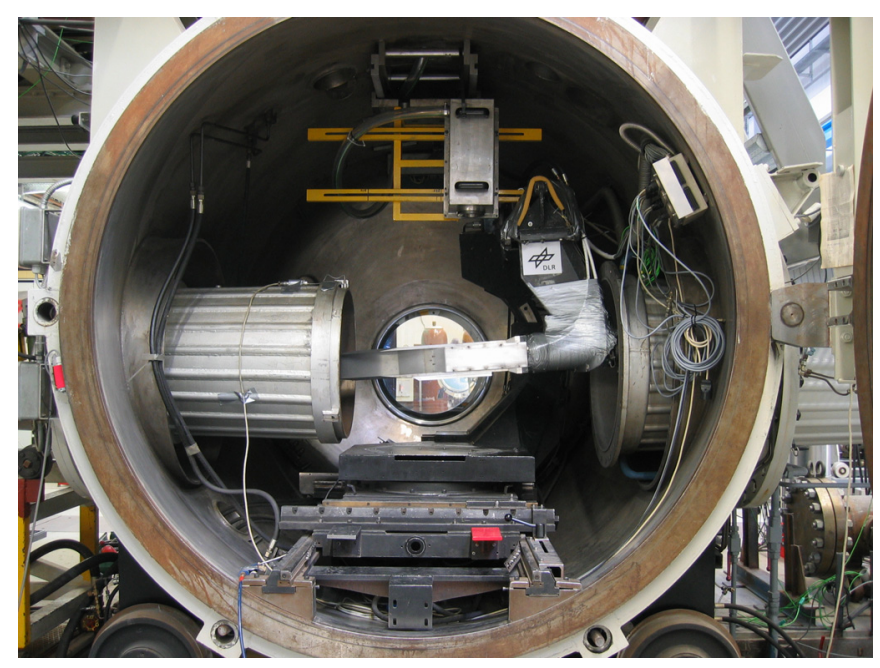

Figure 4: Inlet Model GK-01 in the Test Chamber of H2K, Setup for IR-Measurements 


\section{Measurement Techniques}

\section{A. Optical Diagnostics}

Four optical windows in the sidewalls allow optical access to the isolator part of the inlet model, as pointed out in Figure 3. These can either be equipped with silica glasses for flow visualization, or, using PEEK and zinc sulphide inserts, to measure the heat loads on the side walls with infrared thermography. The measurement procedure for the IR-thermography is described later on.

For flow visualization, a coincidence Schlieren system is installed at the hypersonic wind tunnel H2K of the DLR Cologne. During this investigation, the system was used in shadowgraph mode.

\section{B. Pressure and Mach Number Measurements}

The inlet model is equipped with 42 static pressure ports along the centreline of the inlet, of which 25 are located on the lower and 17 on the upper wall. Furthermore, a Pitot rake with five Pitot tubes distributed over the height of the isolator is integrated on the centerline at the proposed interface of the isolator and the combustion chamber, i.e. at $x=585 \mathrm{~mm}$ from the leading edge of the inlet. This Pitot rake can be shifted $25 \mathrm{~mm}$ to the left and right of the centerline. A commercial Pressure Systems Inc. 8400 system using a 32-PSI module was used for the pressure measurements. Both the results of the static and Pitot pressure measurements are displayed as pressure coefficients. The accuracies in the determination of the pressure coefficients have been calculated to range from $\pm 3.8-5.6 \%$ for static and $\pm 3.4-3.8 \%$ for Pitot pressures. The results from the Pitot pressure measurements are also used to calculate the Mach number of the flow at the entrance to the combustion chamber. For this procedure, it has to be differentiated between supersonic and subsonic flow. For supersonic flow, the ratio of Pitot and static pressure $p_{\text {Pitot }} / p_{s t} \leq 1.8939$ and for subsonic flow, $p_{\text {Pitot }} / p_{s t}>1.8939$. In the first case, the Mach number can be calculated directly by

$$
M_{\text {Pitot }}=\sqrt{\frac{2}{\gamma-1}\left[\left(\frac{p_{\text {Pitot }}}{p_{\text {st }}}\right)^{\frac{\gamma-1}{\gamma}}-1\right]}
$$

In the second case, the Mach number has to be determined iteratively by solving equation 2:

$$
\frac{p_{\text {Pitot }}}{p_{\text {st }}}=\left(\frac{(\gamma+1)^{2} M_{\text {Pitot }}^{2}}{4 \gamma M_{\text {Pitot }}^{2}-2(\gamma-1)}\right)^{\frac{\gamma}{\gamma-1}} \frac{1-\gamma+2 \gamma M_{\text {Pitot }}^{2}}{\gamma+1}
$$

The determination of the accuracy for this procedure is quite difficult since it is not possible to measure the static pressure directly at the Pitot tube but instead, the pressure from the nearest wall pressure port hast to be used. Assuming a variation of the static pressure of $\pm 10 \%$ over the height of the isolator at the place of the Pitot rake results in a relative error of the Mach number of $\pm 5-6 \%$. However, experience showed that while this assumption is valid for most of the experiments, the variation of the static pressure can be significantly higher in some cases, especially when the isolator flow is already partially subsonic or a shock is present in between the Pitot tube and the static pressure port that is being used.

The Pitot pressure measurements are further used to determine the total pressure recovery $\pi$ as well as the kinetic energy efficiency $\eta_{k e}$ of the inlet, which are defined as

$$
\begin{gathered}
\pi=\frac{p_{t, \text { Pitot }}}{p_{t 0}} \\
\eta_{k e}=1-\frac{2}{(\gamma-1) M_{\infty}^{2}}\left[\left(\frac{1}{\pi}\right)^{\frac{\gamma-1}{\gamma}}-1\right]
\end{gathered}
$$




\section{Mass Flow Determination}

During the tests, the inlet is mounted on a conical throttle, which is used to simulate the backpressure of the combustion chamber, and also serves as a mass flow meter. Assuming a one-dimensional flow and sonic condition in the throat of the throttle, the mass flow can be calculated with the procedure from Triesch and Krohn [12].

The mass capture ratio if the inlet is defined as

$$
m_{C R}=\alpha \frac{\dot{m}_{\text {inlet }, \text { exit }}}{\dot{m}_{0}},
$$

where $\alpha$ is a calibration factor determined by calibrating the device according to DIN-1952 [13]. In the concerning region of interest, the values of this factor vary between $0.99<\alpha<1.02$. The smallest cross-section area of the throttle, designated by index 4 , is calculated with the position of the conical and the geometric dimensions of the throttle by

$$
A_{D, t h}=\pi \cdot s \cdot\left(r_{H}+r_{4}\right) .
$$

The Mach number in the settling chamber before the throttle (position 3) can then be determined by iteratively solving equation 5 :

$$
\frac{A_{D 3}}{A_{D, t h}}=\frac{1}{M_{D 3}}\left(\frac{1+\frac{\gamma-1}{2} M_{D 3}^{2}}{\frac{\gamma-1}{2}}\right)^{\frac{\gamma+1}{2(\gamma-1)}}
$$

Using the static pressure measured before the throttle (at position 3), the mass flow can be calculated with the total temperature $T_{t 0}$ and $M_{D 3}$ by

$$
\dot{m}_{D}=\frac{p_{D 3}}{\sqrt{R T_{t 0}}} A_{D 3} \sqrt{\gamma} M_{D 3} \sqrt{1+\frac{\gamma-1}{2} M_{D 3}^{2}} .
$$

The static pressure $\mathrm{pD} 3$ is taken as the average value of four pressure ports located around the settling chamber of the throttle. With the mass flow going through the capture area $A_{0}$ of the inlet, which can be calculated by the free stream conditions of the wind tunnel, the mass flow ration according to equation 3 can the be determined. The accuracy of this method is in the range of $\pm 3 \%$.

Besides the use as a mass flow meter, the throttle also has the important task of imposing a backpressure on the inlet and thus simulation pressure fluctuations in the combustion chamber of a scramjet inlet. This is achieved by lateral movement of the conical plug of the throttle and thus changing the throat area of the throttle as described by equation 4 . This is expressed by the throttle degree $\Delta$, defined as

$$
\Delta=\left(1-\frac{A_{D, t h}}{A_{0}}\right) \cdot 100
$$

For the backpressure ratio, which is used in the following discussion, the static pressure at the location of the Pitot rake is used, where the proposed interface of the inlet and combustion chamber is located.

\section{Wall Heat Flux Measurements}

The determination of wall heat fluxes is a very important task in the design of scramjet engines, especially for the selection of cooling mechanisms as well as materials. In this investigation, heat flux measurements of the sidewalls of the internal flow path as well as the external ramps have been conducted. For the evaluation of the heat fluxes, the chronological development of the surface temperature distribution of the model was recorded with an infrared camera. At the DLR Cologne, a FLIR Systems ThermaCAM SC-3000 is used for this [14]. This camera can be mounted inside of the wind tunnel in an aluminium box as shown in Figure 4.

$$
6
$$


The recorded surface temperature data can then be used as the boundary condition for the numerical integration of the nonlinear, one-dimensional heat equation. A detailed description of this procedure can be found in [8]. Here, only the basic equations are displayed in equations 8 and 9, with temperature dependent material properties:

$$
\begin{gathered}
\rho(T) c_{V}(T) \frac{\partial T}{\partial t}=\frac{\partial}{\partial n}\left(\lambda(T) \frac{\partial T}{\partial n}\right) \\
\rho(T) c_{V}(T) \frac{\partial T}{\partial t}=\frac{\partial \lambda(T)}{\partial n} \frac{\partial T}{\partial n}+\lambda(T) \frac{\partial^{2} T}{\partial n^{2}} \Rightarrow \rho(T) c_{V}(T) \frac{\partial T}{\partial t}=\frac{\partial \lambda(T)}{\partial T}\left(\frac{\partial T}{\partial n}\right)^{2}+\lambda(T) \frac{\partial^{2} T}{\partial n^{2}}
\end{gathered}
$$

In order that this one-dimensional approach is valid, there should not be any significant heat fluxes in the plane of the observed surface. This is achieved by the use of a material with very low heat conductivity, PEEK ${ }^{\circledR}$. This material ensures that the temperature gradient perpendicular to the surface is dominant, and those within the surface plane can be neglected. The temperature dependent material properties are provided by the Institute of Material Science of the German Aerospace Center in Cologne and well known, and thus guarantee sufficient accuracy.

Once the convective wall heat fluxes have been determined, the dimensionless Stanton can be determined by

$$
S t=\frac{\dot{q}_{c o n v}}{\rho_{\infty} u_{\infty} c_{p, a i r}\left(T_{r e c}-T_{w)}\right.} .
$$

With the recovery factor $r=0.9$ the recovery temperature $T_{\text {rec }}$ is defined by

$$
T_{\text {rec }}=\left(1+r \frac{\gamma-1}{2} M_{\infty}^{2}\right) T_{\infty} .
$$

An analysis of all uncertainties of this procedure resulted in maximum errors of $\pm 5 \%$ for the heat fluxes and $\pm 20 \%$ for the Stanton number.

\section{Results}

During the experiments, the inlet proved to be very robust concerning changes of the angle of yaw. The inlet started in all the test runs, where an angle of yaw of up to $4^{\circ}$ was already set up before the beginning of the wind tunnel run. In the cases, where there is no back pressure imposed on the inlet, the static pressure ratio of the inlet is $p / p_{\infty} \approx 36$ and remains constant for values of $\beta$ up to $5^{\circ}$. Hereby, $p$ is the static pressure at the interface of the isolator and the combustion chamber and $p_{\infty}$ is the free stream static pressure. If the throttle degree, which determines the backpressure ratio $p / p_{\infty}$ that is imposed on the inlet, is increased during the test run, the limiting throttle degree, at which inlet unstart occurs, slightly decreases with increasing angle of yaw. At $\beta=0^{\circ}$, inlet unstart usually happens at $\Delta=86 \%$, corresponding to $p / p_{\infty}=176$, and at $\beta=4^{\circ}$, this happens at about $\Delta=85 \%$ or $p / p_{\infty}=155$. This shows that the angle of yaw up to $\beta=4^{\circ}$ has only a very minor effect on the operational range of the inlet. This is also illustrated in Figure 5, which shows the influence of the angle of yaw on the mass capture ratio (MCR) of the inlet.

As can be seen, for values of $\beta$ up to $4^{\circ}$ the mass capture ratio only drops by less than $4 \%$. It also confirms that inlet unstart at high throttle degrees occurs sooner for $\beta=3^{\circ}$ and $\beta=4^{\circ}$. The increase of $\beta$ from $4^{\circ}$ to $5^{\circ}$, however, brings a much larger change. The decline of the MCR is much bigger, and the inlet flow becomes unstable much sooner, already at $\Delta=81 \%$. This, together with the results presented later on, suggests that a strong change in the flow structure occurs at the transition from $4^{\circ}$ to $5^{\circ}$. At theses higher angles of yaw, i.e. $\beta=4^{\circ}$ and $5^{\circ}$ the inlet also seemed to be more likely to show fluctuations in the flow, also designated as inlet buzzing. This, however, only occurred at rather high backpressure ratios.

The total pressure recovery $\pi$ as well as the kinetic energy efficiency $\eta_{k e}$ of the inlet are slightly decreased by the angle of yaw. At $\beta=0^{\circ}, \pi=0.113$ and $\eta_{k e}=0.913$. For $\beta=5^{\circ}$, the values are $\pi=0.109$ and $\eta_{k e}=0.910$, respectively. 


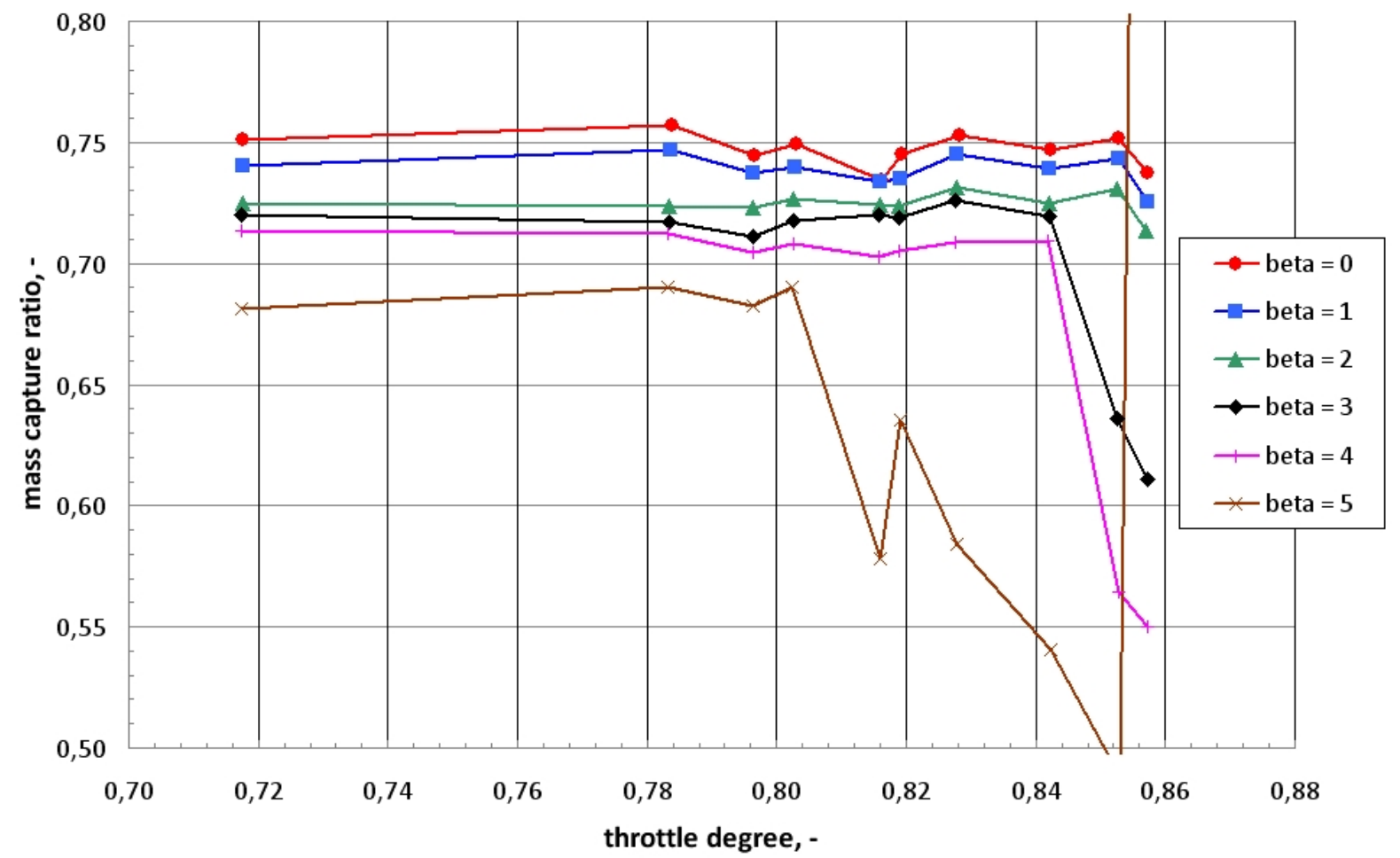

Figure 5: Mass Capture Ratio

\section{A. Internal Flow Field}

The following graph shows the static pressure distribution in terms of the dimensionless pressure coefficient $c_{p}$ for the variation of the angle of yaw from $\beta=0^{\circ}$ to $4^{\circ}$, without any imposed backpressure. The angle of yaw was already set up before the start of each test run. The shadowgraph images clearly show how the shock structure and separation bubble in the throat change when increasing $\beta$.

In the case where $\beta=0^{\circ}$, a large separation zone develops in the throat area through the interaction of the lip shock with the boundary layer on the ramp. The separation shock of this bubble creates another, smaller separation bubble on the cowl, at the position of the second static pressure port $(x=0.425 \mathrm{~m})$. This is also visible in the peak value of the static pressure at this point. On the lower wall of the inlet, the maximum value is reached at about $x=$ $0.45 \mathrm{~m}$, where both the separation and the reattachment shock of this separation bubble on the cowl hit the lower wall. It does not create any separation in this area. The reattachment shock of the large separation bubble at the lower wall, however, causes a second separation area on the upper wall. The separation and reattachment shocks of the this last separation zone can be seen to be reflected all the way through the isolator, and thus create the typical pattern of alternating pressure maxima on the upper and lower walls. For $\beta=4^{\circ}$, the flow structure is quite different. There is only a small separation zone visible in the inlet throat. Unlike in the first case, this separation appears to not be caused by the interaction of the lip shock with the ramp, since the shock angle of the lip shock is smaller and hits the ramp a little further downstream. Thus, the separation zone is located just upstream of the point of shockboundary-layer interaction on the lower wall.

Furthermore, an additional shock can be seen coming into the picture from the left, which is almost parallel to the second. It is very difficult to tell where this shock originates from. This shock is only visible for $\beta=4^{\circ}$, but not for any small angles of yaw. Apparently, it is also the reason, why for $\beta=4^{\circ}$, the highest value of $c_{p}$ is reached at the location of the first pressure port, while for all other configurations it is at the second one, which is where the separation shock from the separation bubble in the throat hits the upper wall. For $\beta=4^{\circ}$, however, it is assumed that this additional shock reaches the upper wall at the location of the first pressure port, although it is hardly visible in the shadowgraph images. Comparing the shock structures in the isolator of the three angles displayed above shows that the reflected shocks move slightly further downstream. This is already visible for the reattachment shock of the separation bubble on the lower wall of the throat. This shift is not large enough, however, that it would also show in the pressure distribution. 

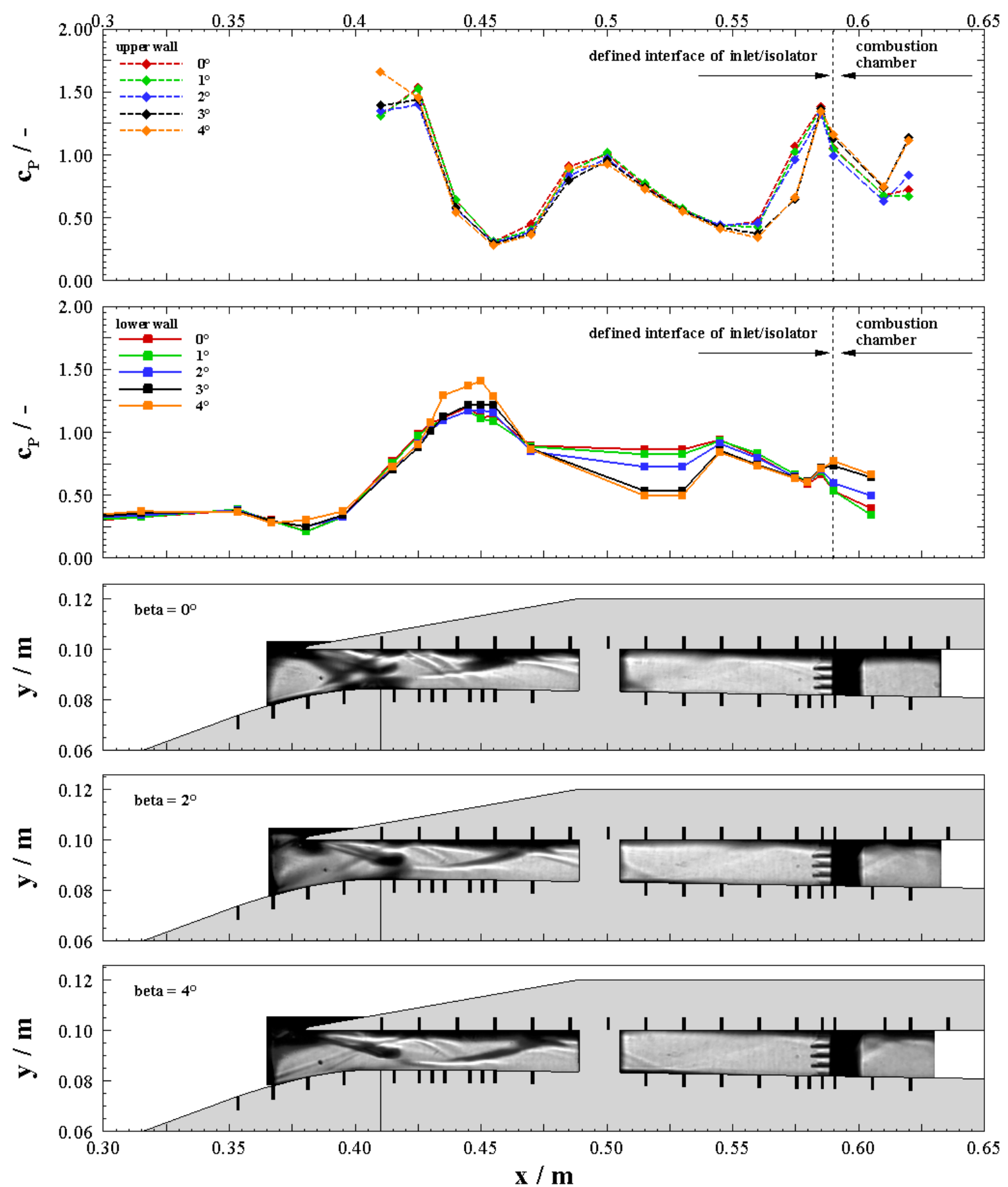

Figure 6: Static pressure distribution and Shadowgraph images for variation of $\beta$ from $0^{\circ}$ to $4^{\circ}$, without imposed backpressure

The influence of $\beta$ on the static pressure is much more distinct along the lower wall of the inlet than on the upper wall. Apparently, a shock emanating from the leeward sidewall of the inlet influences the flow close to the cowl lip and the throat of the inlet, resulting in higher pressure with increasing $\beta$ at both the lip as well as the on the lower wall at the beginning of the isolator part of the inlet. On the other hand, in the downstream part of the isolator there is a region, where the pressure decreases with increasing angle of yaw, suggesting the existence of an expansion wave from the windward sidewall of the inlet. This leads to assume that both the shocks as well as expansion waves 
which are induced by the sidewalls, continue all the way through the isolator of the inlet. This also provides evidence, that the flow becomes highly asymmetric through the angle of yaw.

Comparing these results to those obtained from wind tunnel runs, where the angle was increased stepwise during the experiments gives some more interesting insights. Apparently, the flow is influenced by hysteresis effects. This can be seen by comparing the changes in the pressure distribution when $\beta$ is increased in figures 6 and 7 . If the angle is constant during the experiments, the pressure at certain spots rises or falls continuously with the angle of yaw, i.e. at the first pressure port of the upper wall, the pressure has its minimum at $\beta=0^{\circ}$ and its maximum at $\beta=4^{\circ}$. Likewise, on the lower wall, in the area behind the throat $(x=450 \mathrm{~mm})$, the pressure again rises continuously with $\beta$ whereas in the area further downstream (between $x=530$ and $560 \mathrm{~mm}$ ) the highest value appears when no yaw angles is present. Looking at Figure 7, however, reveals that when $\beta=0^{\circ}$ at the start of the experiment and then stepwise increased during the test run, the pressure does not change continuously but shows some fluctuations. At the lower wall in the isolator, the pressure first drops, reaching a minimum at $\beta=2^{\circ}$, but then rises and falls again with each further increase of $\beta$. A similar behaviour can be observed in the throat region, where $c_{p}$ first slightly drops, then reaches its maximum value at $\beta=3^{\circ}$ and then falls again. The results from the first pressure port on the upper wall show a similar pattern.

A second interesting observation is that the influence of $\beta$ on the changes in the pressure distribution is much smaller, when $\beta$ is changed during the test run. In the isolator part, for example, the maximum difference in the values of $c_{p}$ is about 0.5 , whereas it is only about 0.3 if $\beta$ is changed during the experiment.

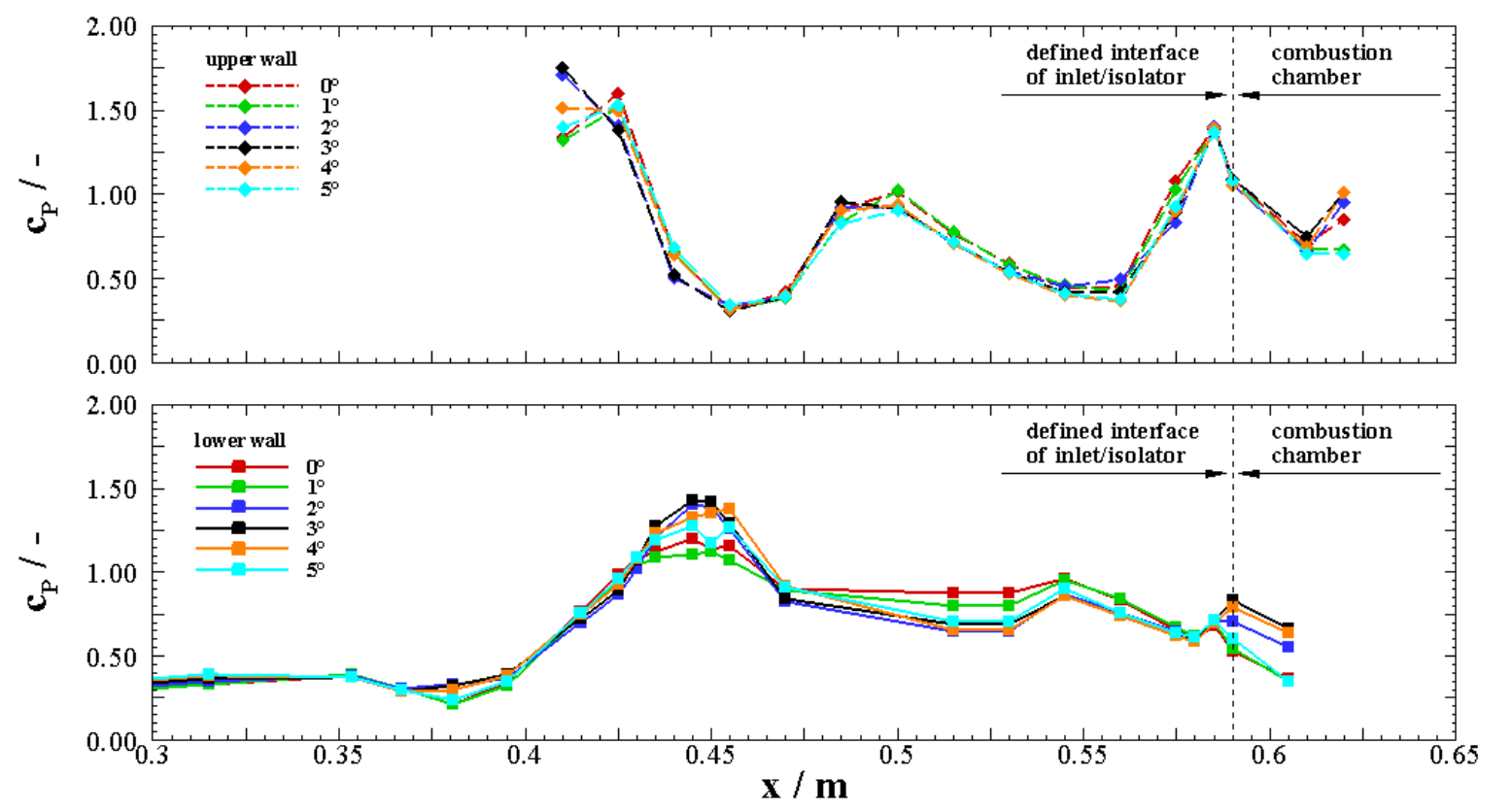

Figure 7: Static pressure along upper and lower wall for stepwise change of $\beta$ during the test run

If there is an additional back pressure imposed on the isolator by the throttle, the picture looks quite a bit different, as the following figures 8 and 9, displaying pressure distributions and shadowgraph images for a back pressure ratio of $p / p_{\infty} \approx 140$, show. At this ratio, the flow along the lower wall of the isolator is subsonic for all values of $\beta$. This can be seen by the steady pressure rise in the isolator up to the back pressure imposed on the inlet by the throttle. If the flow was still supersonic, the increase in pressure would occur through shocks, creating a pattern with peaks, as it is visible on the upper wall. 

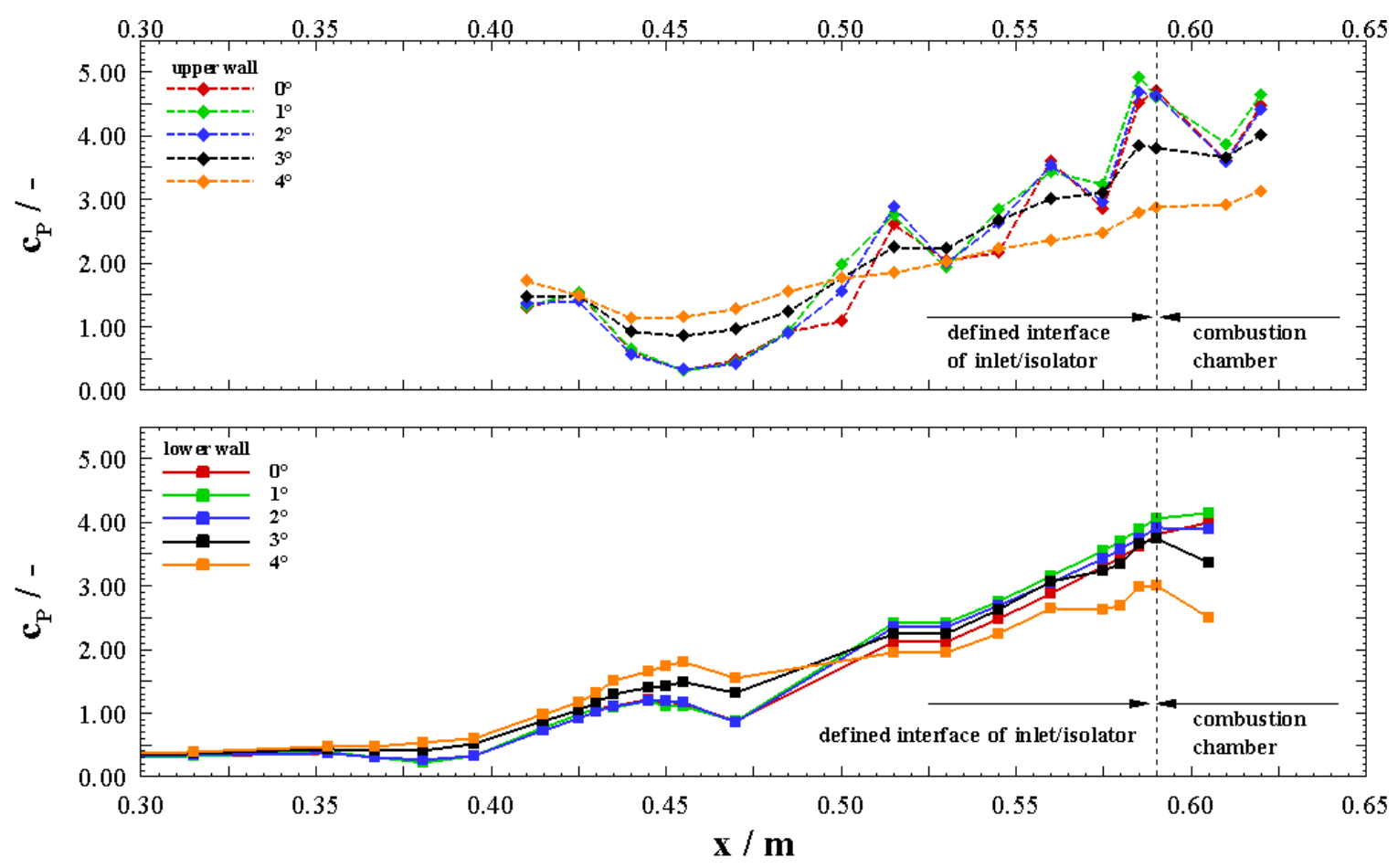

Figure 8: Pressure distribution $p / p_{\infty} \approx 140$ when $\beta$ was constant during wind tunnel run

Here, the jumps in the pressure distribution give evidence of the existence of a shock train, and thus supersonic flow up to $\beta=3^{\circ}$. The flow turns subsonic when $\beta$ is increased to $4^{\circ}$. It is also visible how the pressure of both the upper and lower half drop and when the flow in the upper half becomes subsonic. The results from the other experiments indicated that in the lower half of the isolator, the flow turns subsonic for $\beta=5^{\circ}$ at $p / p_{\infty} \approx 95$. For backpressure ratios greater than $p / p_{\infty} \approx 105$ the flow in the lower half is subsonic for all angles. On the upper wall, the backpressure can be increased up to $p / p_{\infty} \approx 155$, before the flow turns subsonic when there is no yaw angle.
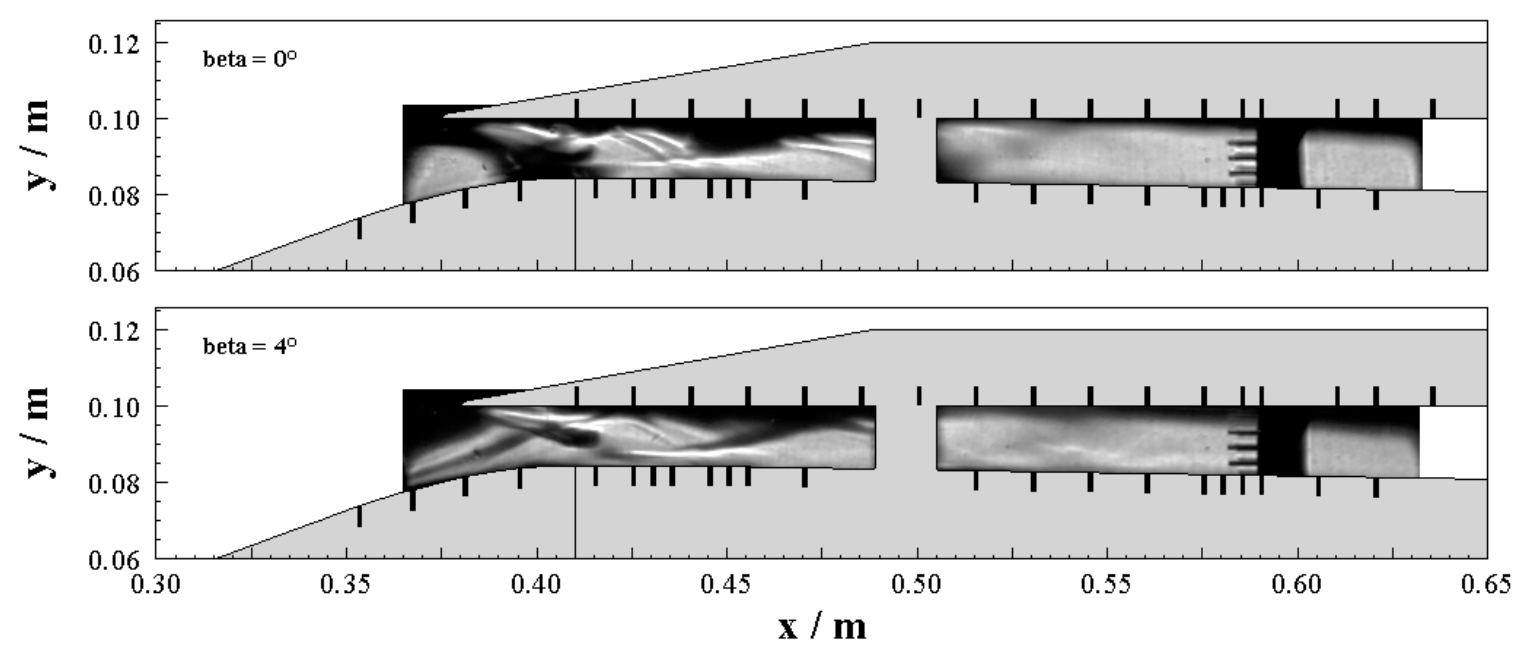

Figure 9: Shadowgraph images for backpressure ratio $p / p_{\infty} \approx 140$

The observations from the pressure distribution are confirmed by the shadowgraph images displayed in Figure 9 . Especially a close look at the Pitot rake reveals, that the flow is supersonic in the upper and subsonic in the lower 
part of the isolator for $\beta=0^{\circ}$, but completely subsonic for $\beta=4^{\circ}$. The throat section of the inlet is not affected by the increased back pressure, it only influences the flow from the area in between the two windows.

In contrast to $\beta$ variation from run to run, the flow at the upper wall is supersonic up to values of $\beta=4^{\circ}$ in the case, where $\beta$ was changed during the test run. The transition to subsonic flow only takes place at $\beta=5^{\circ}$, as the pressure distribution in figure 6 illustrates.
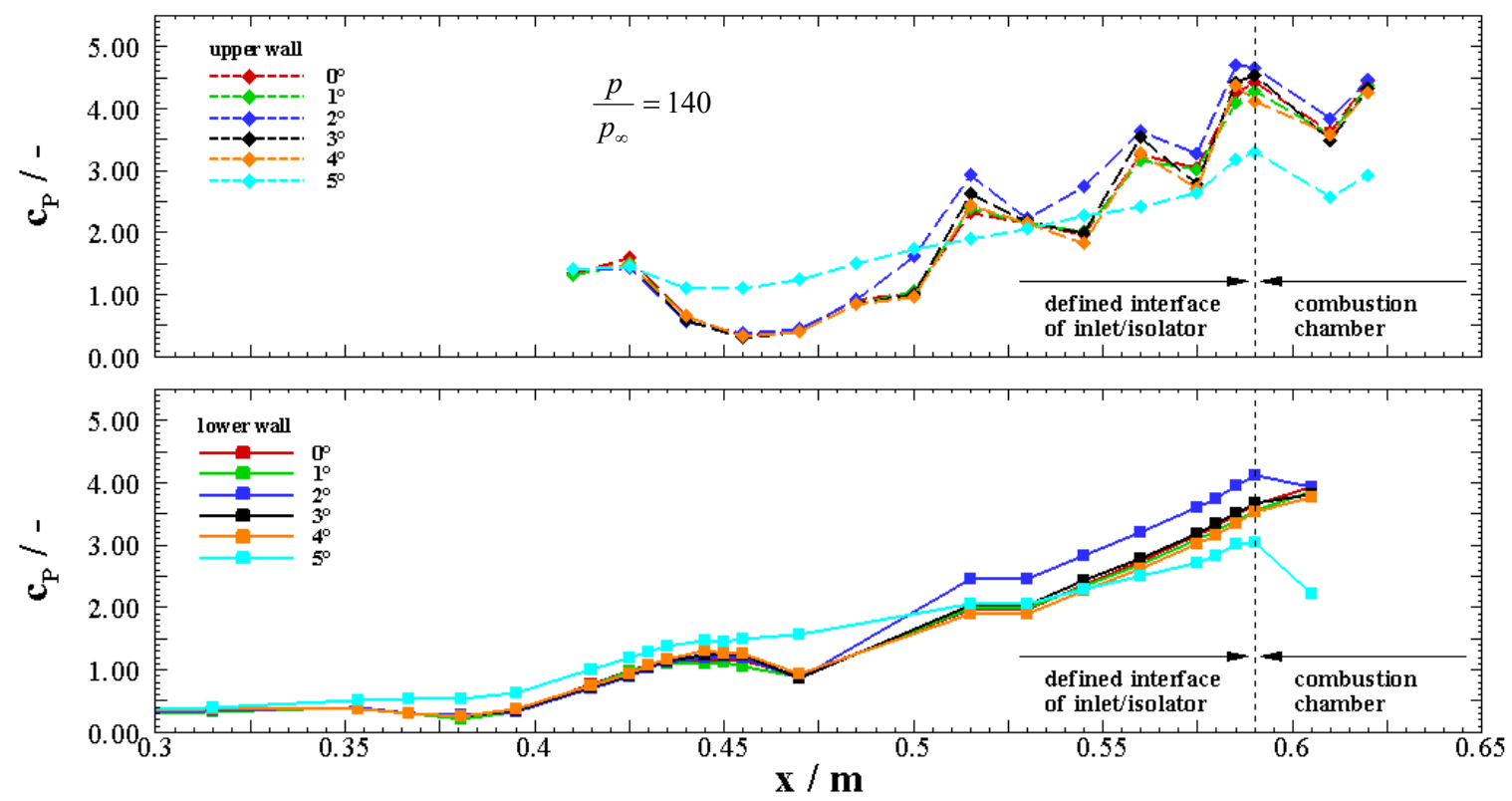

Figure 10: Pressure distribution for variation of $\beta$ from $0^{\circ}$ to $5^{\circ}$ during wind tunnel run at a backpressure ratio of $p / p_{\infty} \approx 140$

The characteristics of Pitot pressures and Mach numbers at the interface of isolator and combustion chamber show very well, how the flow is influenced by three-dimensional effects through the application of different angles yaw. This is displayed in Figure $11 \mathrm{a}$ and $\mathrm{b}$ for the variation of $\beta$ from $0^{\circ}$ to $4^{\circ}$. The case shown is the one, where the angle of yaw has already been set up before the start of the wind tunnel run and kept constant during each run. Without imposed backpressure, only minor effects of the yaw angle are visible. For all angles, the Pitot pressure in the upper half of the isolator is much higher than in the lower part. The Mach number distribution, on the other hand, is quite constant over the isolator height. It is interesting to note is the different development of the Pitot pressure at the varying Pitot tubes. As opposed to the static pressure distributions where the measurements continuous changes (i.e. continuously increased or declined) for this case, the Pitot pressure first drops from $\beta=0^{\circ}$ to $\beta=2^{\circ}$, but then rises again when the angle is increased to $4^{\circ}$ or vice versa, depending on which Pitot tube is considered. At the second Pitot tube from the top, the pressure first rises and then declines, for the first and fourth Pitot tubes, it is the other way round. In the middle of the isolator, there is hardly any change visible. The influence on the Mach number is much smaller than on the Pitot pressure. The tendencies of the changes are the same, however.

For the higher backpressure ratio of $p / p_{\infty} \approx 140$ the influence of the yaw angle on the Pitot pressure is much stronger. While the change is not very significant up to $\beta=2^{\circ}$, the flow is somewhat turned upside down when $\beta$ is increased to $3^{\circ}$ and $4^{\circ}$. Up to $\beta=2^{\circ}$, the pressure distribution is still higher in the upper half than in the lower half. At this back pressure ratio, however, the value of the top most Pitot tube is much closer to the second one, which still shows the highest value of $c_{p}$. At $\beta=3^{\circ}$, the Pitot pressure is quite constant over the height of the isolator, already showing the tendency, that the highest value is achieved at the second tube from the bottom. For $\beta=4^{\circ}$, the pressure in the upper part decreases significantly while it almost stays at the same level as at $\beta=3^{\circ}$ in the lower half. The Mach number measurements for this case have to be regarded very carefully. They also show the same tendencies from the influence of the yaw angle, i.e. only very little change from $0^{\circ}$ to $2^{\circ}$, and an increase in the lower and decrease in the upper half when the angle is raised to $4^{\circ}$.

However, as already mentioned in the description of the measurement procedure, this calculation can obtain significant errors through the difference in the static pressure at the point of the Pitot tube and the wall pressure 
which is used to calculate the Mach number. As explained in the discussion of figures 8 and 9 , the flow is already completely subsonic for $\beta=4^{\circ}$ at this pressure ratio, but the diagram in figure $11 \mathrm{~b}$ shows supersonic speed in the lower half at this point. For the other angles, however, the Mach number distributions appear to be more accurate.

(a)

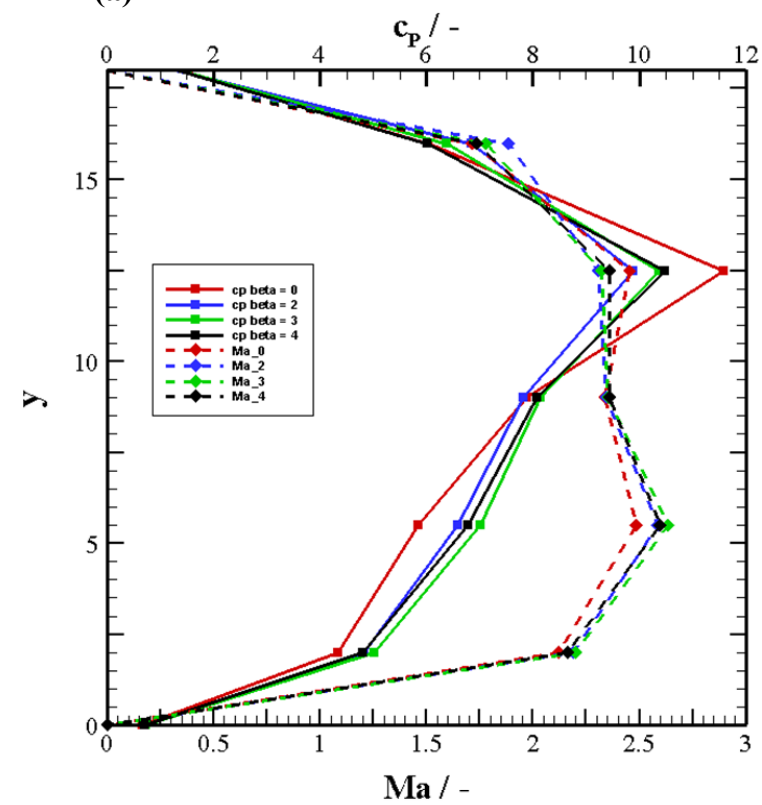

(b)

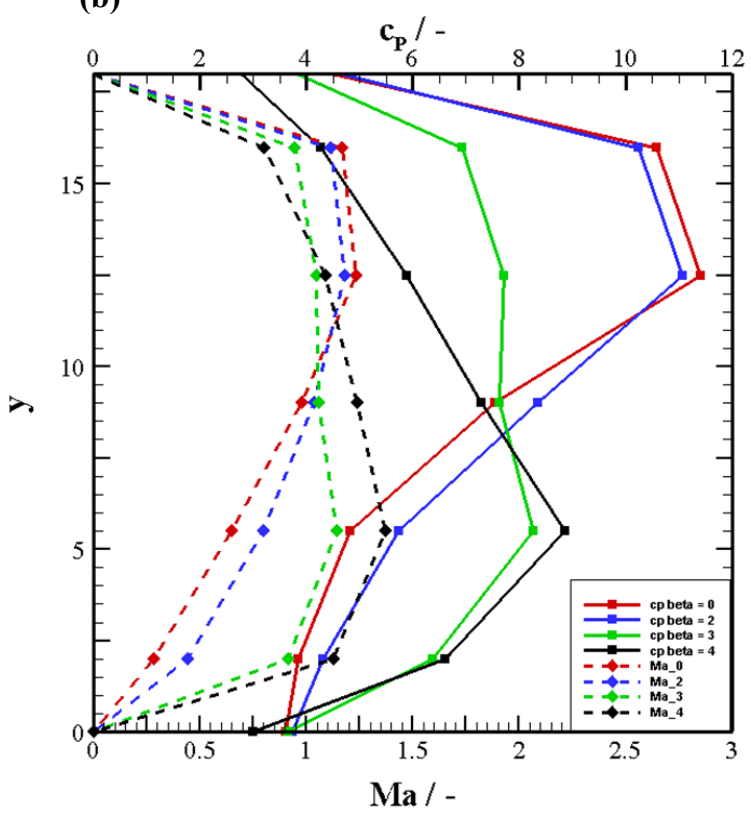

Figure 11a and b: Pitot and Mach number measurements at (a) $p / p_{\infty} \approx 30$ and (b) $p / p_{\infty} \approx 140$

\section{B. External Flow Field}

In the present study, the analysis of the external flow field was mostly done by the use of IR-thermography, as the number of pressure ports in this area is too small in order to obtain meaningful results. However, there are plenty of examples of investigations on the flow field over double wedges similar to this one by other authors, for example $[15,16]$. There has also been an intensive study of the external compression of the present configuration in the frame of the research training group by Neuenhahn $[17,18]$ and Haeberle [2].

The analysis of the external ramps with IR-thermography reveals some insight into the effects of yaw angle to the flow topology in the external compression part of the inlet. This is displayed in Figure 12 for $\beta=0^{\circ}$ and Figure 13 for $\beta=4^{\circ}$.

In the case where no angle of yaw is present, a separation region develops in the kink between the first and second ramp. The flow on the first ramp is still laminar, that is why the shock of the second ramp easily causes the boundary layer to separate at this kink. After the reattachment of the flow, transition takes place and the boundary layer turns turbulent, thus strongly increasing the heat loads on the surface of the second ramp. In the stream wise direction, the highest loads are present in the centre region of the second ramp. Closer to the lip, where the isentropic expansion surface begins, heat loads start to decline again. Furthermore, the image shows clear signs of the existence of Görthler-vortices on the second ramp [19]. 


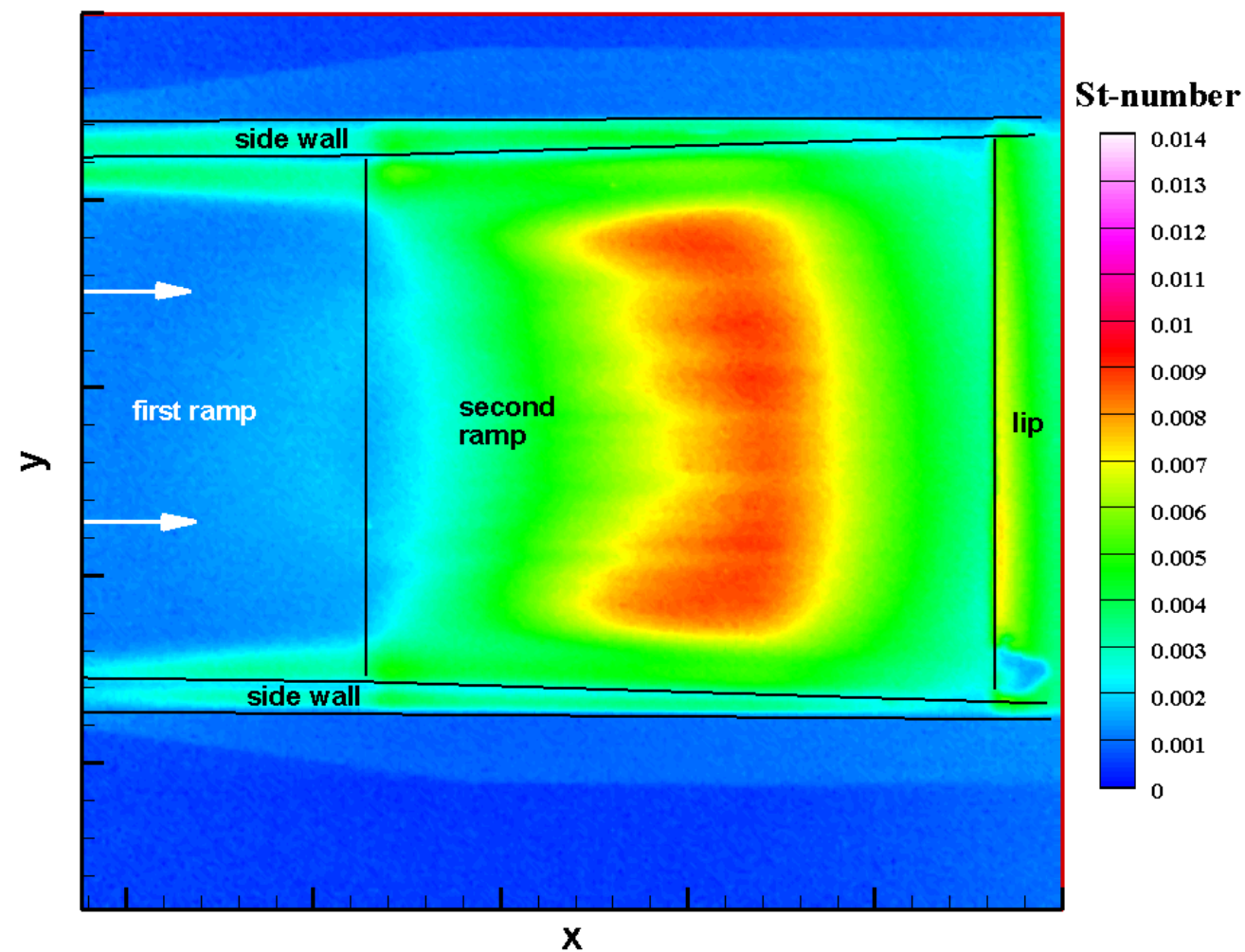

Figure 12: St-Number distribution on the external ramps for $\beta=0^{\circ}$

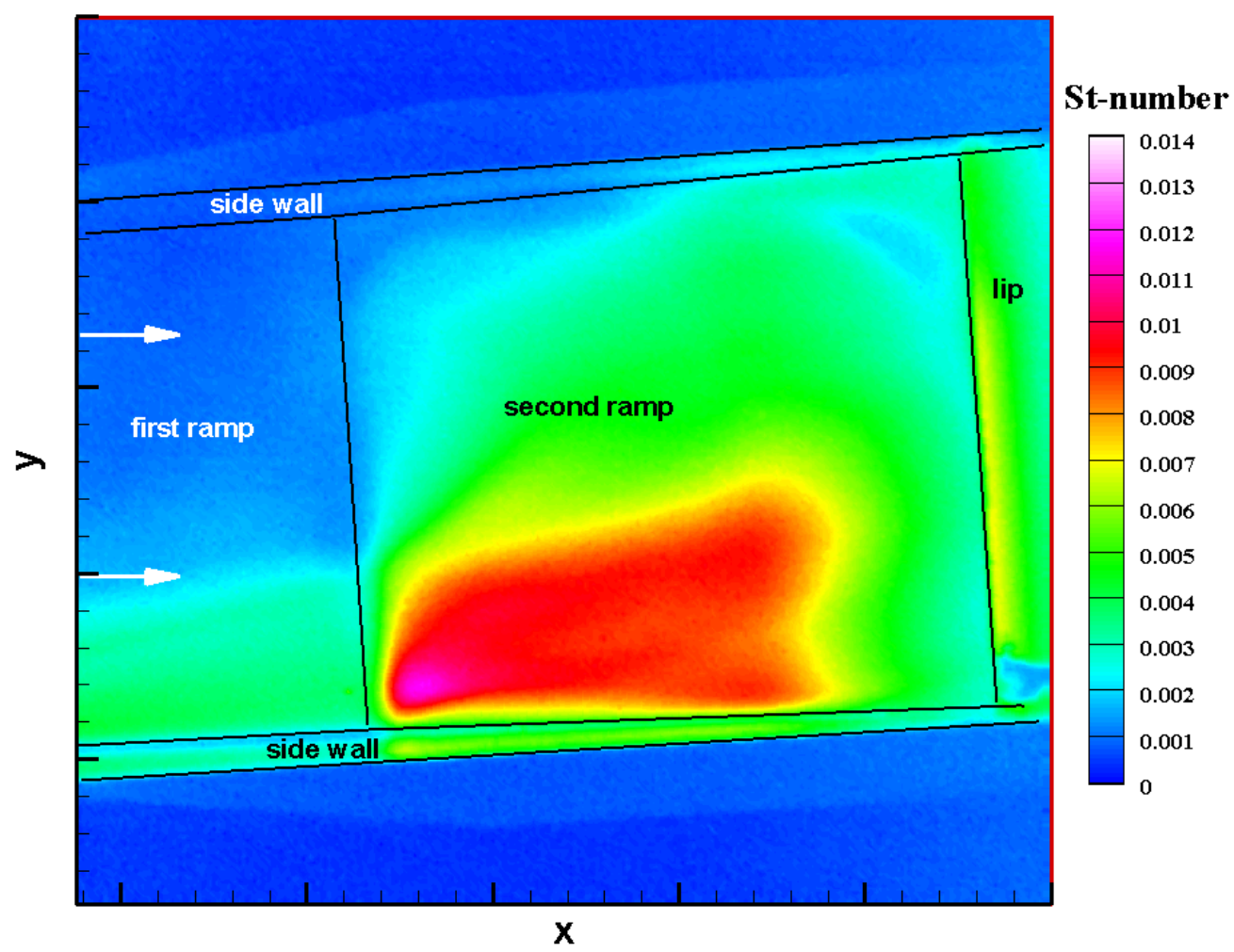

Figure 13: St-Number distribution on the external ramps for $\beta=4^{\circ}$

14

American Institute of Aeronautics and Astronautics 
Figure 13 displayed above shows the Stanton number distribution on the external compression ramps at a yaw angle of $\beta=4^{\circ}$. In this case, the point of maximum heat loads is in the corner of the kink of the first and second ramps and the leeward sidewall. It is very difficult to exactly tell what effect is causing this. Presumably, it is the interaction of several phenomena. The angle of yaw induces a sidewall shock which interacts with the first ramp shock and thus creates a very complex corner flow. This is described in detail by Goonko et al. [9]. A bridging shock forms between the ramp and sidewall shocks. From the points, where the bridging shock and the sidewall and ramp shocks interact, further shocks originate which lead to the respective walls. This shock structure interacts in the kink with the second ramp shock. Furthermore, corner vortices are also present in this area. It is assumed that this multiple shock-shock and shock-boundary-layer interaction together with the vorticity causes the strong increase in the St-number in this area.

In the upper half of the second ramp, the St-number is much smaller than in the case where $\beta=0^{\circ}$. The flow in this area is presumably influenced by an expansion wave caused by the windward sidewall of the inlet. This area is limited by a rather sharp line which is already visible on the first ramp. It appears likely that this is the position of the sidewall shock.

The angle of yaw probably also influences the transition point of the inlet, although the obtained results do not allow for any conclusion as to where it is in this case. It might also influence the much higher heat loads in the corner region between the first and second ramps but it is not possible to tell for sure.

\section{Conclusion}

The current experimental campaign was especially motivated by the need of experimental data concerning the use of this inlet regarding a flight experiment to see how it reacts to the inflow coming in at an angle of yaw. It could be demonstrated that the inlet still operated very well at angles of yaw of up to $\beta=5^{\circ}$ without the use of the passive boundary layer bleed, which is integrated into the inlet throat. At this point, the pressure rise in the inlet is quite constant at about $p / p_{\infty} \approx 36$ for angles up to $\beta=5^{\circ}$. This value is close to the design point of the inlet. At this point, the angle of yaw has only very little effect on the entrance condition into the combustion chamber, i.e. the Mach number is around $M=2$ to $M=2.5$. Furthermore, the decline in efficiency of the inlet was small, as shown by the changes of the total pressure recovery $\pi$ and the kinetic energy efficiency $\eta_{k e}$.

At $p / p_{\infty} \approx 140$, the flow at the interface of the isolator and the combustion chamber is already partially subsonic for $\beta=0^{\circ}$, and completely subsonic for angles larger than $\beta=3^{\circ}$. The backpressure ratio, at which inlet unstart occurs, decreases from $p / p_{\infty} \approx 176$ at $\beta=0^{\circ}$ to $p / p_{\infty} \approx 155$ for $\beta=4^{\circ}$. However, at the higher angles, the inlet seemed to be more likely to show fluctuations in the flow, also known as inlet buzzing, especially when the angle was increased further to $\beta=5^{\circ}$. At the transition from $4^{\circ}$ to $5^{\circ}$ the overall change of the measured values was larger than for smaller angles.

The investigation of the external ramps revealed strong changes in the distribution of the heat loads on the ramp surfaces. While for $\beta=0^{\circ}$, the values of the Stanton-number were highest in the centre part of the second ramp, the spot with highest Stanton-number in the cases with yaw angle is located at the windward sidewall just after the kink between the first and second ramps. The angle of yaw obviously has a strong influence on the flow structure on the external ramps and appears to have significant effects on the transitional behavior of the boundary layer.

The data gathered in this campaign provide a valuable addition to the database of the operation characteristics of hypersonic inlets, and can well be used for the validation of CFD-results.

\section{Acknowledgments}

The authors would like to thank the German Research Council for their support within the research training group GRK 1095/2 as well as the DLR Cologne. Further thanks go to Michael Kosbow and Dirk Lütz for their assistance during the experiments.

\section{References}

[1] Weigand, B., Gaisbauer, U., Reinartz, B., Kau, H.-P., and Schröder, W., Das Graduiertenkolleg 1095/1: "Aerothermodynamische Auslegung eines Scramjet-Antriebssystems für Zukünftige Raumtransportsysteme", DGLR-Paper, 2006-127, 2006.

[2] Häberle, J., Untersuchungen zum Externen und Internen Strömungsfeld eines Scramjet Triebwerkseinlaufs bei Unterschiedlichen Betriebspunkten, DLR Forschungsbericht, ISRN DLR-FB-2009-14, 2009. 
[3] Häberle, J. and Gülhan, A., Investigation of Two-Dimensional Scramjet Inlet Flowfield at Mach 7, Journal of Propulsion and Power, Vol. 24, No. 3, May-June 2008, pp. 446-459.

[4] Häberle, J. and Gülhan, A., Experimental Investigation of a Two-Dimensional and a Three-Dimensional Scramjet Inlet at Mach 7, Journal of Propulsion and Power, Vol. 24, No. 5, September-October 2008, pp. 1023-1034.

[5] Heiser, W. H. and Pratt, D. T., Hypersonic Airbreathing Propulsion, AIAA Education Series, Washington, DC, 1st ed., 1994.

[6] Anderson, B. H., Design of Supersonic Inlets by a Computer Program Incorporating the Method of Characteristics, NASA Technical Note, TN-D-4960, January 1969.

[7] Boyce, R., Gerard, S., and Paull, A., The Hy-Shot scramjet flight experiment - flight data and CFD calculations compared, AIAA-2003-7029, 2003.

[8] Henckels, A. and Gruhn, P., Study on Aerothermal Effects of Viscous Shock Interaction in Hypersonic Inlets, Proceedings of the Fifth European Symposium on Aerothermodynamics for Space Vehicles, ESA SP-563, Cologne, February 2005.

[9] Goonko, Y. P., Latypov, A. F., Mazhul, I. I., Kharitonov, A. M., Yaroslavtsev, M. I., and Rostand, P., Structure of Flow over a Hypersonic Inlet with Side Compression Wedges, AIAA Journal, Vol. 41, No. 3, March 2003, pp. 436-447.

[10] Niezgodka, F.-J., Der Hyperschallwindkanal H2K des DLR in Köln-Porz (Stand 2000), DLR Mitteilung, 2001-01, January 2001 .

[11] Kantrowitz, A. and duP. Donaldson, C., Preliminary Investigation of Supersonic Diffusors, NACA Wartime Report, ACR L5D20, May 1945.

[12] Triesch, K. and Krohn, E.-O., Verwendung von Kegeldüsen zur Drosselung und Durchsatzmessung bei Überschalleinläufen, DFVLR-Bericht, IB-39113-83-A-04, 1984.

[13] DIN Deutsches Institut für Normung e.V., Durchflußmessung mit Blenden, Düsen und Venturirohren in voll durchströmten Rohren mit Kreisquerschnitt, DIN 1952 (VDI Durchflussmeßregeln), July 1982.

[14] FLIR Systems, ThermaCAM SC-3000, Users Manual.

[15] Bleilebens, M., Einfluss der Wandtemperatur auf die Stoß/Grenzschicht-Wechselwirkung an einer Rampe im Hyperschall, Dissertation, RWTH Aachen, ISBN 3-8322-3811-5, 2004.

[16] Delery, J., Shock/Shock and Shock-Wave/Boundary-Layer Interactions in Hypersonic Flows, AGARD-FDP-VKI, VKI, Brussels, 30 May - 3 June 1988.

[17] Neuenhahn, T. and Olivier, H., Influence of the wall temperature and entropy layer effects on double wedge shock boundary layer interactions, AIAA-2006-8136, 2006.

[18] Neuenhahn, T. and Olivier, H., Numerical Study of Wall Temperature and Entropy Layer Effects on Transitional Double Wedge Shock Wave/Boundary Layer Interactions, 26th International Symposium on Shock Waves, July 15 - 202007.

[19] Häberle, J. and Gülhan, A., Investigation of the Flow Field of a 2D SCRAM-Jet Inlet at Mach 7 with optional Boundary Layer Bleed, 43rd AIAA/SAE/ASEE Joint Propulsion Conference and Exhibit, AIAA 2007-5068, July 2007. 